\title{
Genetic relationship between lactation curve traits in the first three parities of dairy cattle
}

\author{
C.B. Wasike ${ }^{1 \#}$, A.K. Kahi ${ }^{2}$ \& K.J. Peters ${ }^{3}$ \\ ${ }^{1}$ Department of Animal Science, School of Agriculture and Food Security, Maseno University, Private Bag, 40105 \\ Maseno, Kenya; ${ }^{2}$ Animal Breeding and Genetics Group, Department of Animal Sciences, Egerton University, P.O. Box \\ 536, 20115 Egerton, Kenya; ${ }^{3}$ Animal Breeding and Genetics Consultant, Sheep and Goat Association of Berlin- \\ Brandenburg, Dieselstr. 10, D 14612 Falkensee, Germany
}

(Received 13 February 2014; Accepted 5 June 2014; First published online 23 August 2014)

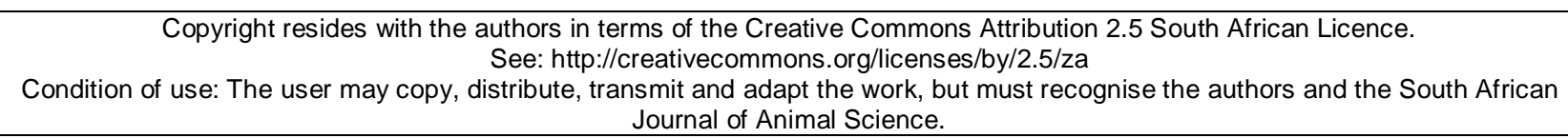
Journal of Animal Science.

\begin{abstract}
In Kenya, selection of dams for the national contract mating scheme is based on 305-day lactation milk yield (TMY) performance across parities. At farm level, only cows that had good TMY performance in previous parity are retained for the subsequent lactation. This strategy has resulted in improved milk production performance, although increased incidences of physiological disorders, mastitis and reduced fertility have been reported in high-yielding cows. Records on functional traits relative to milk yield are scant. Properties of lactation curves could be used indirectly to explain the productive and functional efficiency of dairy cows. This study assesses the relationship between lactation traits, based on the lactation curve, to evaluate the effects of selection for TMY on lactation curve properties and to assess the effects of selection decisions based on first lactation on performance in later lactations. A repeatability analysis revealed negative genetic correlations between peak milk yield (MYmax) and persistency (S); MYmax and days in milk at peak (DIMP); and TMY and DIMP. Genetic correlations were positive between DIMP and S, and TMY and MYmax. This implies that selection for high TMY would result in high MYmax and a reduction in DIMP. This alters the shape of the lactation curve, shifting production pressure to early lactation, which aggravates a negative energy balance, thus compromising the physiological integrity of the cow. Continuous selection for high TMY could be responsible for the reported decline in reproductive efficiency and lactation physiology. Correlation estimates between traits in different parities were bidirectional (correlation estimates changed signs (+/-) in different parities), implying that selection decisions made in lactation 1 may not have similar outcomes in lactations 2 and 3. Selection at farm level should be optimised by using records from three parities, as is done in the contract mating scheme.
\end{abstract}

Keywords: Correlation estimates, reproductive performance, test-day milk yield

\#Corresponding author: wasikebwire@yahoo.co.uk

\section{Introduction}

Lactation milk yield is an important trait in selection of dairy cattle all over the world. Selection of dams for the national contract mating scheme in Kenya is based on lactation performance across parities. At farm level, the survival of the cow to the next lactation depends largely on her previous lactation performance. This strategy of selecting breeding stock, based on their milk production potential, has resulted in considerable improvement in milk yield (Ojango \& Pollott, 2001). However, cases of increased infertility, reduction in production herdlife, and metabolic and mammary disorders have become common in Kenyan dairy herds.

Continuous selection for milk production traits (test-day milk yield, 305-day milk yield and total lactation milk yield) may affect functional traits such as fertility, somatic cell count and mastitis, depending on the correlation between them (Appuhamy et al., 2007; Jamrozik et al., 2010). This implies that the reported infertility and increase in mammary and metabolic disorders in Kenyan herds may be as a result of the previous selection practices. The availability of records on milk production and reproduction traits in the Kenyan dairy cattle population has enabled investigations into the forms and types of relationships between these traits (Ojango \& Pollott, 2001; Ilatsia et al., 2007). However, records are not available on udder health and metabolic disorders in lactating animals, such as somatic cell count, mastitis, milk fever, displaced abomasums and ketosis. Consequently, the relationships between milk production and these traits cannot be 
estimated directly. Based on knowledge of lactation physiology, the energy balance during lactation and reproductive efficiency in early lactation might indirectly explain the observed declining reproductive performance and increased udder health problems in Kenyan herds. This could be achieved by drawing inferences from relationships between milk yield and lactation curve traits.

A lactation curve is a graphical representation of daily milk production ability of a cow throughout the entire lactation and is useful in explaining the physiology of milk production in cows (Pollott, 2000). Milk yield is interpreted in physiological terms as a function of the quantity of the alveoli cells in the udder at the onset of lactation, their milk secretion ability and their proliferation and death during lactation (Dijkstra et al., 1997; Capuco et al., 2003). A typical lactation curve starts with an increase in milk production from parturition to peak production, then declines until drying off. This curvature leads to three important components of the lactation curve, namely milk yield at peak lactation (MYmax), days in milk at peak milk yield (DIMP), and the extent to which the animal maintains peak milk yield, also referred to as persistency (S), the study of which provides insight into lactation physiology. Knowledge of this physiology is important for management decisions and animal breeding.

Studies have shown that lactation curve traits are correlated with functional traits. For instance, correlation has been demonstrated between persistency and udder health, and reproduction performance of cows (Jakobsen et al., 2002; Muir et al., 2004; Appuhamy et al., 2007). This implies that, depending on the correlation between the traits, selection decisions based on lactation curve traits could influence functional traits that are important in efficiency of milk production. Quantified estimates of association between lactation milk yield and lactation curve traits could explain physiological issues reported in Kenyan herds and guide future selection decisions. The correlation between milk yield and lactation curve traits has not been estimated in the Kenyan dairy cattle population, and consequently the relationship between these traits cannot be quantified. The objective of this study is to estimate the phenotypic and genetic relationships between lactation curve traits and 305-day milk yield in the dairy cattle population of Kenya in order to assess the effects of cow selection on the basis of lactation milk yield on lactation curve properties in order to provide an explanation of the declining functional performance reported in the herds; to assess the effect of selection decisions in first lactation on subsequent lactation performance; and to demonstrate how the utility of milk yield records could be enhanced by exploiting genetic relationships between traits.

\section{Material and Methods}

Milk yield records from the first three parities of Ayrshire, Holstein Friesian and Jersey cows were extracted from the national dairy cattle database at the Livestock Recording Centre (LRC) in Naivasha, Kenya. These records included test-day milk yield (TDMY) and 305-day lactation milk yield (TMY) of cows that calved between 1994 and 2010. The TDMY records were from monthly milk yield samples collected on the evening of every fourteenth day and the morning of every fifteenth day. The first test-day record was taken on the fifth day postpartum. For animals lactating beyond the 305 days, TMY was achieved by right truncation of records at 305 days in milk (DIM), resulting in a dataset that had ten TDMY samples per lactation. The data were edited to remove records of lactations following abortions, lactation with missing test-day yields, and lactations with inconsistent dates of birth, calving and drying. Further edits involved removal of records of milk yield sampled earlier than the fifth day postpartum, in which case the subsequent milk sample was considered the first test-day sample. In addition, where sampling was done more than once in a month, milk records were removed in favour of samples closer to the fourteenth and fifteenth days of sampling. A total of 61240 test-day records were available for analysis after the edits. A summary of the structure and descriptive statistics of the data is presented in Table 1.

Lactation curve traits, namely milk yield at peak lactation (MYmax), days in milk at peak milk yield (DIMP) and persistency (S), were computed from lactation curve parameters estimated from the test-day using the incomplete gamma function (Wood, 1967).

$$
Y_{t}=a t^{b} e^{-c t}
$$

where $Y_{t}$ is the test-day milk yield at DIM; and $t, a, b$ and $c$ are parameters representing a scaling factor associated with initial milk yield, pre-peak and post-peak curvatures, respectively. The function was fitted to TD-data using PROC NLIN of SAS (SAS, 2004), invoking a Marquardt computing algorithm. Convergence was assumed when the difference between error sums of squares in successive iterations was less than $10^{-6}$. MYmax was calculated as $a(b / c)^{b} e^{-b}$; DIMP was expressed as $b / c$; and $S$ was computed as $c^{-(b+1)}$. Modelling lactation curves with the incomplete gamma function results in four shapes of the lactation curve depending on the sign (positive $(+)$ or negative $(-))$ of the $b$ and $c$ parameters, namely standard $(+b,+c)$, continuously decreasing $(-b,+c)$, continuously increasing $(+b,-c)$, and reverse of standard $(-b,-c)$ lactation curves. Computation of the curve traits (MYmax, DIMP and S) was based on the lactations that manifested 
the standard lactation shape only. This explains the lower number of records for curve traits than the TMY in Table 1.

Furthermore, the relationship between lactation curve traits and TMY was evaluated by estimation of phenotypic and genetic correlations using a multivariate animal model. The pedigree file, which spanned four generations and consisted of 7094 animals from 537 sires and 995 dams, was used to construct the numerator relationship matrix for genetic analysis. The maximum paternal and maternal family size was 123 and 8 , respectively. In the first case, a repeatability animal model was used in which MYmax, DIMP, S and TMY records were fitted, treating records from different lactations as repeated observations of the same trait, which yielded four traits in the analysis. The following model (in matrix notation) was used:

$$
y=X \beta+Z a+W p+e
$$

where $\boldsymbol{y}$ is a vector of the observations for the various traits in the analysis (MYmax, DIMP, S and TMY); $\boldsymbol{\beta}$ is a vector of fixed effects, including breed, parity, contemporary group of herd year, season of calving, and linear and quadratic covariance of dam's calving age and days in milk at first test-day; $\boldsymbol{a}, \boldsymbol{p}$ and $\boldsymbol{e}$ are vectors of random effect of the animal, permanent environmental effect and residual effects, respectively. $\boldsymbol{X}, \boldsymbol{Z}$ and $\boldsymbol{W}$ are incidence matrices that relate fixed effects, random animal and permanent environmental effects, respectively, to the observations. Whereas matrix $\boldsymbol{Z}$ contains all animals (with and without records), matrix $\boldsymbol{W}$ contains only animals with records.

Let $a$ and pe denote the vectors of additive genetic and permanent environmental effects, respectively, and $e$, the vector, residual errors. Also, let $A$ be the numerator relationship matrix between animals and $I$ the identity matrix. The (co)variance structure for the analysis would thus be described as:

$$
\begin{aligned}
& V(a)=\sum A \otimes A \\
& V(p e)=\sum C \otimes I \\
& V(e)=\sum E \otimes I \\
& \operatorname{Cov}(a, p e)=0
\end{aligned}
$$

where $\Sigma_{A}$ is the $n \times n$ matrix of additive genetic covariances $\left(\sigma_{A i j}\right), \Sigma_{c}$ is the matrix of permanent environmental effects $\left(\sigma_{\mathrm{Cij}}\right), \Sigma_{E}$ the matrix of error covariances $\left(\sigma_{\mathrm{Eij}}\right), \boldsymbol{I}$ is an identity matrix and $\otimes$ denotes the direct matrix product. The covariance between $\mathbf{a}$ and $\boldsymbol{p e}$ was assumed to be zero.

Second, the relationships between traits were assessed by considering observations on traits in different parities as being different, which gave rise to 12 traits ((MYmax, DIMP, S and TMY) $\times 3$ parities) for the analyses. This was done to project the consequences of selection of cows based on milk production performance in first parity on subsequent parities. Consequently, the following simple animal model was used in the analyses:

$$
y=X \beta+Z a+e
$$

where $\boldsymbol{y}$ is a vector of observations for the ith trait in parity $\mathrm{j}, \boldsymbol{\beta}$ is a vector of fixed effects influencing the ith trait in parity j, $\boldsymbol{a}$ and $\boldsymbol{e}$ are vectors of random effect of the animal and residual effects, respectively for the ith trait, $\boldsymbol{X}$ and $\boldsymbol{Z}$ are incidence matrices that relate observations for the ith trait to fixed and random animal effects, respectively.

Estimates of phenotypic and genetic parameters were obtained using WOMBAT (Meyer, 2006). The program uses average Information ( $\mathrm{Al}$ ), and a combination of proximate and expectation maximization (PX-EM) algorithms to estimate covariance components and genetic parameters. During the iterations, parameters at convergence of the preceding round of iterations were used as new priors to the subsequent iteration runs to ensure a global REML convergence. Convergence was assumed when the difference in log likelihoods in successive iterations and the change in the parameters were less than $10^{-4}$. For the multivariate analysis, three runs were performed for the analysis of lactation 1 traits against lactation 2 traits, lactation 1 against lactation 3 traits, and lactation 2 against lactation 3 traits. The resulting genetic parameter estimates were pooled by weighting each estimate by the inverse of its sampling variance.

\section{Results}

The structure of data used for analysis and mean dairy performance of the cattle breeds in the three parities is presented in Table 1. Holstein Friesian cattle had the highest TMY, followed by Jersey, while Ayrshire had the lowest TMY across parities. Jersey cattle attained peak milk yield (DIMP) earliest. MYmax was highest in Holstein Friesian and lowest in Ayrshire. Parity 1 had the lowest TMY and MYmax and this 
variable increased as parity advanced from Parities 1 to 3 . Cows attained peak milk production much later in Parity 1 relative to Parities 2 and 3.

Table 1 Data structure and mean performances for the various traits

\begin{tabular}{|c|c|c|c|c|c|c|c|c|c|c|c|}
\hline \multirow{2}{*}{ Breed } & \multirow{2}{*}{ Parity } & \multirow{2}{*}{ Lactations } & \multirow{2}{*}{ Herds } & \multicolumn{4}{|c|}{ Number of records } & \multicolumn{4}{|c|}{ Mean performance } \\
\hline & & & & MYmax & DIMP & $S$ & TMY & MYmax & DIMP & $\mathrm{S}$ & TMY \\
\hline \multirow[t]{3}{*}{ Ayrshire } & 1 & 325 & 35 & 214 & 214 & 214 & 325 & 13.48 & 63.79 & 1596.61 & 2991.47 \\
\hline & 2 & 225 & 26 & 144 & 144 & 144 & 225 & 15.27 & 59.18 & 1441.71 & 3214.20 \\
\hline & 3 & 183 & 30 & 130 & 130 & 130 & 183 & 15.70 & 57.71 & 1345.27 & 3425.36 \\
\hline \multirow[t]{3}{*}{ Holstein } & 1 & 1414 & 80 & 980 & 980 & 980 & 1414 & 18.94 & 67.04 & 1482.01 & 4516.58 \\
\hline & 2 & 1154 & 79 & 854 & 854 & 854 & 1154 & 22.99 & 49.84 & 1059.02 & 5109.81 \\
\hline & 3 & 852 & 64 & 657 & 657 & 657 & 852 & 25.01 & 49.71 & 1049.09 & 5406.30 \\
\hline \multirow[t]{3}{*}{ Jersey } & 1 & 264 & 10 & 200 & 200 & 200 & 264 & 15.99 & 56.51 & 1504.95 & 3939.67 \\
\hline & 2 & 205 & 10 & 163 & 163 & 163 & 205 & 18.89 & 42.82 & 936.93 & 4224.90 \\
\hline & 3 & 173 & 11 & 155 & 155 & 155 & 173 & 18.90 & 47.83 & 1094.30 & 4413.67 \\
\hline
\end{tabular}

$\mathrm{S}=$ persistency; MYmax = milk yield at peak lactation; DIMP = days in milk at peak lactation;

$\mathrm{TMY}=$ 305-day lactation milk yield.

Estimates of genetic parameters for MYmax, DIMP, S and TMY that were obtained using repeatability animal models are presented in Table 2. Heritability of S, MYmax, DIMP and TMY was $0.171,0.2,0.134$ and 0.171 , respectively. Permanent environmental variance as a proportion of phenotypic variance was lowest for $S(0.077)$ and highest for TMY (0.328). Estimates of repeatability ranged from 0.161 for DIMP to 0.499 for TMY.

Table 2 Estimates of genetic (below diagonal) and phenotypic (above diagonal) correlations between lactation curve traits and 305-day milk yield, their heritability $\left(\mathrm{h}^{2}\right)$, permanent environmental variance as a proportion of phenotypic variance $\left(c^{2}\right)$ and repeatability $(\mathrm{t})$ with associated standard errors in parentheses

\begin{tabular}{lccccccc}
\hline Traits & $\mathrm{S}$ & MYmax & DIMP & TMY & $\mathrm{h}^{2}$ & $\mathrm{c}^{2}$ & $\mathrm{t}$ \\
\hline $\mathrm{S}$ & 1 & $-0.120(0.01)$ & $0.747(0.03)$ & $0.048(0.01)$ & $0.171(0.02)$ & $0.077(0.01)$ & $0.248(0.03)$ \\
MYmax & $-0.093(0.12)$ & 1 & $-0.159(0.02)$ & $0.740(0.02)$ & $0.200(0.04)$ & $0.252(0.05)$ & $0.452(0.03)$ \\
DIMP & $0.983(0.07)$ & $-0.275(0.02)$ & 1 & $0.077(0.01)$ & $0.134(0.05)$ & $0.027(0.02)$ & $0.161(0.04)$ \\
TMY & $0.053(0.011)$ & $0.976(0.05)$ & $-0.129(0.05)$ & 1 & $0.171(0.03)$ & $0.328(0.02)$ & $0.499(0.01)$
\end{tabular}

$\mathrm{S}$ = persistency; MYmax = milk yield at peak lactation; DIMP = days in milk at peak lactation;

$\mathrm{TMY}=305$-day lactation milk yield.

Genetic correlation between S and MYmax was negative but low. This estimate had a relatively high SE (0.12). Negative genetic correlations were observed between DIMP and MYmax, and TMY and DIMP. Genetic correlations between DIMP and S, and TMY and MYmax were positive and high. A positive correlation was observed between TMY and S, although this was low. Phenotypic correlations between S and MYmax and MYmax and DIMP were low and negative. S and DIMP and MYmax and TMY had high positive phenotypic correlation estimates. Phenotypic correlations between S and TMY and DIMP and TMY were positive but low.

Genetic correlation estimates between lactation curve traits and TMY in different parities are presented in Table 3. Genetic correlations between lactation curve traits between parities varied. $S$ in Parity 1 was negatively correlated with S $(-0.022)$ and DIMP $(-0.114)$ in Parity 2 , and MYmax $(-0.081)$ and TMY $(-0.200)$ in Parity 3. However, correlations with other traits were positive. The correlations between $S$ 
and the other traits were low, except with DIMP in Parities 1 and 3, where moderate estimates were observed. Correlation between MYmax in Parity 1 and TMY in Parity 1, MYmax, DIMP and TMY in Parities 2 and 3 , were positive with coefficients ranging from 0.016 to 0.934 . The trait, however, was negatively correlated with DIMP in Parity 1, S in Parities 2 and 3. The estimates of these negative correlations ranged from low to medium ( -0.008 to -0.477 ). DIMP in Parity 1 had negative correlation with MYmax and TMY in Parities 1, 2 and 3. Positive and moderate correlations were observed between DIMP and S in Parities 1 and 2, although this dropped in Parity 3. The correlation between DIMP in Parity 1 and DIMP in Parities 2 and 3 was positive and moderate. TMY in Parity 1 was positively correlated to $\mathrm{S}$ and MYmax in Parities 1 and 2 , DIMP and TMY in Parity 2, and MYmax and TMY in Parity 3.

Genetic correlations between S in Parity 2 and all other traits in Parities 2 and 3 were positive, except MYmax in Parity $2(-0.096)$ and $3(-0.419)$, and TMY in Parity $3(-0.006)$. The highest correlation between S and other traits was observed with DIMP in Parity 2 (0.959) and the lowest with TMY in Parity $3(-0.006)$. Correlation between MYmax in Parity 2 and DIMP and S in Parities 2 and 3 were negative and low, respectively. Correlation with the other traits in Parities 2 and 3 was, however, positive. Medium to high correlation was observed between this trait and TMY in Parity 2 (0.846) and MYmax in Parity 3 (0.524). DIMP in Parity 2 was positively correlated with TMY in Parities 2 and 3. The correlation coefficient was, however, low. The correlation between DIMP in Parity 2 and S, MYmax and DIMP in Parity 3 was low to moderate and positive. TMY in Parity 3 was positively correlated to all traits in Parity 3 except S. Correlations between traits in Parity 3 were negative with low to medium coefficients, except for those between $S$ and DIMP (0.938), and MYmax and TMY (0.891), where the correlations were highly positive.

Phenotypic correlations between S, MYmax, DIMP and TMY in the first three parities are presented in Table 3. Phenotypic correlations between S in Parity 1 and other traits were low, except with DIMP where a high correlation (0.711) was noted. Negative correlations were observed between the trait and MYmax in Parity $1(-0.101)$ and $3(-0.06)$ and TMY in Parity 3 (-0.017). MYmax in Parity 1 was negatively correlated with DIMP in Parity 1 and S in Parity 2. Correlation with other traits was positive. A high positive correlation was observed between MYmax and TMY in Parity 1 (0.805). Correlations between DIMP in Parity 1 and other traits were generally low and positive. However, DIMP was negatively correlated with MYmax in all the parities. TMY in Parity 1 and other lactation traits were positively correlated except S in Parity $2(-0.003)$, where the correlation was negative. The correlations with MYmax in Parity 2 and TMY in Parities 2 and 3 were fairly moderate.

Phenotypic correlation between S and DIMP in Parity 2 was fairly high and positive (0.699). The correlations between $S$ and other traits were low and positive, except between the trait and MYmax in Parity $2(-0.103)$ and TMY in Parity $3(-0.057)$, where the correlation estimates were negative. MYmax in Parity 2 was highly and positively correlated with TMY in the same parity. Low to moderate positive correlations were observed between the trait and MYmax and TMY in Parity 3. Low negative correlations were noted between this trait and a few traits in Parities 2 and 3. DIMP in Parity 2 was negatively correlated with all traits in Parity 3 , although the correlation coefficients were low. The correlations between TMY in Parity 2 and Parity 3 traits were positive but low. Phenotypic correlations between DIMP and S of Parity 3 (0.773), and TMY and MYmax (0.686), were high and positive. Other correlation estimates between traits in Parity 3 were low, with negative correlations between MYmax and S (-0.137), and DIMP and MYmax (-0.156).

\section{Discussion}

The relatively low estimates of heritability from the repeatability model indicate that the proportion of the phenotypic performance of candidate animals influenced by genetics was low. Consequently, the phenotype of the animal would not be a reliable indicator of its underlying genetic potential. This implies that more progress may be achieved by selecting animals based on their breeding values, which exploit the animals' genetic ability than based on their phenotypic performance. The estimates in this study may more or less differ from other studies owing to factors such as the type of population analysed and the methodology. Generally, heritability estimates for TMY were lower than those reported in literature, while those of S were similar (Ojango \& Pollott, 2001; Cole \& Null, 2009). Repeatability estimates provide information on the animals' future producing ability in the herd (Mrode, 2005). These estimates were low for S and DIMP and high for MYmax and TMY, depicting the cows' ability to perform better in subsequent lactations. 
Table 3 Estimates of genetic (below diagonal) and phenotypic (above diagonal) correlations and their standard errors in parenthesis between lactation curve traits in Parities 1, 2 and 3

\begin{tabular}{|c|c|c|c|c|c|c|c|c|c|c|c|c|}
\hline \multirow[b]{2}{*}{ Trait } & \multicolumn{4}{|c|}{ Parity 1} & \multicolumn{4}{|c|}{ Parity 2} & \multicolumn{4}{|c|}{ Parity 3} \\
\hline & $S_{1}$ & $\operatorname{MYmax}_{1}$ & DIMP $_{1}$ & $\mathrm{TMY}_{1}$ & $\mathrm{~S}_{2}$ & $\operatorname{MYmax}_{2}$ & $\mathrm{DIMP}_{2}$ & $\mathrm{TMY}_{2}$ & $\mathrm{~S}_{3}$ & $\operatorname{MYmax}_{3}$ & DIMP $_{3}$ & $\mathrm{TMY}_{3}$ \\
\hline $\mathrm{S}_{1}$ & & $\begin{array}{c}-0.101 \\
(0.02)\end{array}$ & $\begin{array}{l}0.711 \\
(0.01)\end{array}$ & $\begin{array}{l}0.023 \\
(0.30)\end{array}$ & 0.05 & $\begin{array}{l}0.008 \\
(0.05)\end{array}$ & $\begin{array}{l}0.028 \\
(0.03)\end{array}$ & 0.032 & 0.115 & $\begin{array}{l}-0.06 \\
(0.09)\end{array}$ & $\begin{array}{l}0.123 \\
(0.08)\end{array}$ & -0.017 \\
\hline $\operatorname{MYmax}_{1}$ & $\begin{array}{c}-0.019 \\
(0.16)\end{array}$ & & $\begin{array}{c}-0.143 \\
(0.02)\end{array}$ & $\begin{array}{l}0.805 \\
(0.01)\end{array}$ & $\begin{array}{l}-0.04 \\
(0.02)\end{array}$ & $\begin{array}{l}0.278 \\
(0.07)\end{array}$ & $\begin{array}{l}0.003 \\
(0.01)\end{array}$ & $\begin{array}{c}0.34 \\
(0.04)\end{array}$ & $\begin{array}{l}0.147 \\
(0.09)\end{array}$ & $\begin{array}{l}0.212 \\
(0.10)\end{array}$ & $\begin{array}{c}0.27 \\
(0.11)\end{array}$ & $\begin{array}{l}0.323 \\
(0.07)\end{array}$ \\
\hline DIMP $_{1}$ & $\begin{array}{l}0.406 \\
(0.61)\end{array}$ & $\begin{array}{c}-0.477 \\
(0.60)\end{array}$ & & $\begin{array}{l}0.071 \\
(0.02)\end{array}$ & $\begin{array}{l}0.096 \\
(0.05)\end{array}$ & $\begin{array}{c}-0.026 \\
(0.02)\end{array}$ & $\begin{array}{l}0.103 \\
(0.03)\end{array}$ & $\begin{array}{l}0.021 \\
(0.01)\end{array}$ & $\begin{array}{l}0.141 \\
(0.10)\end{array}$ & $\begin{array}{l}-0.01 \\
(0.10)\end{array}$ & $\begin{array}{l}0.128 \\
(0.11)\end{array}$ & $\begin{array}{l}0.071 \\
(0.07)\end{array}$ \\
\hline $\mathrm{TMY}_{1}$ & $\begin{array}{l}0.051 \\
(0.70)\end{array}$ & $\begin{array}{l}0.934 \\
(0.03)\end{array}$ & $\begin{array}{c}-0.401 \\
(0.60)\end{array}$ & & -0.003 & $\begin{array}{l}0.356 \\
(0.04)\end{array}$ & $\begin{array}{l}0.088 \\
(0.04)\end{array}$ & 0.51 & 0.168 & $\begin{array}{l}0.204 \\
(0.09)\end{array}$ & $\begin{array}{l}0.233 \\
(0.08)\end{array}$ & 0.399 \\
\hline $\mathrm{S}_{2}$ & -0.022 & $\begin{array}{c}-0.008 \\
(0.11)\end{array}$ & 0.555 & 0.022 & & $\begin{array}{c}-0.103 \\
(0.02)\end{array}$ & $\begin{array}{l}0.699 \\
(0.01)\end{array}$ & $\begin{array}{l}0.107 \\
(0.07)\end{array}$ & 0.206 & $\begin{array}{l}0.153 \\
(0.07)\end{array}$ & $\begin{array}{l}0.068 \\
(0.08)\end{array}$ & -0.057 \\
\hline $\mathrm{MYmax}_{2}$ & $\begin{array}{l}0.081 \\
(0.03)\end{array}$ & $\begin{array}{l}0.334 \\
(0.16)\end{array}$ & -0.364 & $\begin{array}{l}0.401 \\
(0.03)\end{array}$ & $\begin{array}{c}-0.096 \\
(0.01)\end{array}$ & & $\begin{array}{c}-0.135 \\
(0.03)\end{array}$ & $\begin{array}{l}0.727 \\
(0.01)\end{array}$ & $\begin{array}{c}-0.022 \\
(0.08)\end{array}$ & $\begin{array}{l}0.244 \\
(0.08)\end{array}$ & $\begin{array}{c}-0.011 \\
(0.04)\end{array}$ & $\begin{array}{l}0.192 \\
(0.07)\end{array}$ \\
\hline DIMP $_{2}$ & $\begin{array}{c}-0.114 \\
(0.03)\end{array}$ & $\begin{array}{l}0.016 \\
(0.01)\end{array}$ & 0.616 & $\begin{array}{l}0.027 \\
(0.02)\end{array}$ & $\begin{array}{l}0.959 \\
(0.06)\end{array}$ & $\begin{array}{c}-0.021 \\
(0.01)\end{array}$ & & $\begin{array}{l}0.113 \\
(0.02)\end{array}$ & $\begin{array}{c}-0.027 \\
(0.09)\end{array}$ & $\begin{array}{c}-0.083 \\
(0.10)\end{array}$ & $\begin{array}{c}-0.006 \\
(0.10)\end{array}$ & $\begin{array}{l}-0.05 \\
(0.04)\end{array}$ \\
\hline $\mathrm{TMY}_{2}$ & 0.084 & $\begin{array}{l}0.408 \\
(0.04)\end{array}$ & -0.330 & 0.515 & $\begin{array}{l}0.117 \\
(0.05)\end{array}$ & $\begin{array}{l}0.846 \\
(0.04)\end{array}$ & $\begin{array}{l}0.153 \\
(0.01)\end{array}$ & & 0.017 & $\begin{array}{l}0.183 \\
(0.06)\end{array}$ & $\begin{array}{l}0.039 \\
(0.06)\end{array}$ & 0.21 \\
\hline $\mathrm{S}_{3}$ & 0.207 & $\begin{array}{c}-0.037 \\
(0.16)\end{array}$ & $\begin{array}{l}0.077 \\
(0.76)\end{array}$ & -0.084 & 0.141 & $\begin{array}{c}-0.083 \\
(0.18)\end{array}$ & $\begin{array}{c}-0.321 \\
(0.25)\end{array}$ & -0.136 & & $\begin{array}{c}-0.137 \\
(0.03)\end{array}$ & $\begin{array}{l}0.773 \\
(0.01)\end{array}$ & $\begin{array}{l}0.021 \\
(0.30)\end{array}$ \\
\hline $\mathrm{MYmax}_{3}$ & $\begin{array}{c}-0.081 \\
(0.32)\end{array}$ & $\begin{array}{l}0.345 \\
(0.22)\end{array}$ & -0.421 & $\begin{array}{l}0.422 \\
(0.18)\end{array}$ & -0.419 & 0.524 & -0.216 & 0.581 & $\begin{array}{c}-0.299 \\
(0.21)\end{array}$ & & $\begin{array}{c}-0.156 \\
(0.03)\end{array}$ & $\begin{array}{l}0.686 \\
(0.02)\end{array}$ \\
\hline $\mathrm{DIMP}_{3}$ & $\begin{array}{l}0.364 \\
(0.30)\end{array}$ & $\begin{array}{l}0.024 \\
(0.20)\end{array}$ & 0.377 & $\begin{array}{c}-0.004 \\
(0.14)\end{array}$ & $\begin{array}{l}0.096 \\
(0.24)\end{array}$ & $\begin{array}{l}0.083 \\
(0.22)\end{array}$ & $\begin{array}{c}-0.345 \\
(0.31)\end{array}$ & $\begin{array}{c}0.03 \\
(0.14)\end{array}$ & $\begin{array}{l}0.938 \\
(0.05)\end{array}$ & $\begin{array}{c}-0.391 \\
(0.23)\end{array}$ & & $\begin{array}{l}0.050 \\
(0.02)\end{array}$ \\
\hline $\mathrm{TMY}_{3}$ & -0.200 & $\begin{array}{l}0.246 \\
(0.14)\end{array}$ & -0.473 & 0.335 & -0.006 & $\begin{array}{l}0.258 \\
(0.31)\end{array}$ & $\begin{array}{l}0.047 \\
(0.41)\end{array}$ & 0.334 & $\begin{array}{c}-0.149 \\
(0.70)\end{array}$ & $\begin{array}{l}0.891 \\
(0.11)\end{array}$ & $\begin{array}{c}-0.262 \\
(0.15)\end{array}$ & \\
\hline
\end{tabular}

$\mathrm{S}=$ persistency; MYmax = milk yield at peak lactation; DIMP = days in milk at peak lactation; TMY = 305-day lactation milk yield. 
Correlation estimates could be positive or negative, depicting the direction of change in one variable when change occurred in the other variable (Bourdon, 2000; Mrode, 2005). The high positive genetic correlation between DIMP and S, and TMY and MYmax implies a strong genetic relationship between the traits owing to pleiotropy. Therefore, selection for genetic improvement of TMY would also result in an increase in MYmax. Similarly, improvement in S could be achieved when selection is aimed at increasing DIMP. Positive correlation estimates between TMY and MYmax, and DIMP and S were reported in the analysis of lactation curves of Spanish Holstein cattle (Rekaya et al., 2000). The negative genetic correlation between MYmax and S, MYmax and DIMP, and TMY and DIMP implies that genes that influence MYmax also influence $S$ and DIMP, but in the opposite directions. Selection for increased MYmax would result in a reduction in S and DIMP, which implies a sharper drop in post peak milk production and early attainment of peak milk yield. Owing to the higher correlation estimate between MYmax and DIMP relative to MYmax and $\mathrm{S}$, the magnitude of response to selection will be better in the former than the latter. Rekaya et al. (2000) similarly obtained negative correlation between MYmax and $\mathrm{S}$, but reported positive estimates between MYmax and DIMP.

Phenotypic correlations depict a strong positive relationship between TMY and MYmax, as well as DIMP and S. This implies that cows with high TMY were likely to attain high MYmax, while high $S$ was closely associated with increase in DIMP. Similar results were observed in a study of phenotypic relationships of health disorders to lactation persistency (Appuhamy et al., 2007). Producers select breeding animals based on the phenotypic value of TMY. This mode of selection is bound to result in improvement in MYmax. Considering the negative phenotypic relationship between MYmax and S and DIMP, which is of greater magnitude than the positive correlation between TMY and S and DIMP, the resultant of phenotypic selection for high TMY would be increased MYmax, which is attained early as a result of reduction in DIMP and a steep post-peak gradient owing to a reduction in persistency.

Practising either genetic or phenotypic selection to improve TMY would result in alteration of the shape of the lactation curve, especially in early stages of lactation. This will have an effect on the lactation physiology energy balance and metabolic processes of the animal. Consequently, there would be effects on the physiological traits such as somatic cell count and clinical mastitis in addition to fertility performance of the cows and occurrence of metabolic disorders such as ketosis, metritis and displaced abomasums (Muir et al., 2004; Appuhamy et al., 2007; Negussie et al., 2008).

From the correlation analysis of traits between lactations, high and positive genetic correlation between TMY and MYmax within the same parity implies a strong genetic relationship. Consequently, selection for increased TMY would result in an increase in MYmax in the same parity in offspring generation. The genetic correlation between these traits of different parities was positive and moderate, indicating a positive correlated response in MYmax and TMY in subsequent parities when selection is done to increase TMY alone or TMY and MYmax in the earlier parity. Positive correlation estimates were also observed between TMY in Parities 1, 2 and 3 in Italian Holsteins (Muir et al., 2007).

Unlike TMY and MYmax, the genetic relationships of $S$ in the three parities, as well as DIMP, were not straightforward. The correlation estimates were either positive or negative between parities. This indicates changes in the genetic control of these components of the lactation curve between parities and thus necessitating careful consideration during selection. This also applied to correlations between TMY and DIMP, and S between parities, where both negative and positive relationships were observed. Muir et al. (2007) observed similar trends in correlations between milk yield and somatic cell count and attributed it to poor data connectivity between trait records in different parities. These kinds of relationships are responsible for undesirable response to selection in single trait selection programmes and selection programmes where selection decisions are based on evaluations from a single parity.

Phenotypic correlations of a trait between parities were unidirectional. This implied that animals, for instance with high TMY in Parity 1, also produced high TMY in subsequent parities. Changes in the sign of correlation estimates were observed between traits in different parities, depicting uni- and bidirectional relationships. A bidirectional relationship between traits between parities implies that selection, for instance for increased TMY in Parity 1, could result in reduction in DIMP in Parity 1 owing to the moderately negative correlation estimate, a mild increase in DIMP in Parity 2 and eventually a mild reduction again in Parity 3. These non-straight forward responses to selection call for an in-depth thought of selection strategies.

The estimates of correlations above indicate that selection for increased milk yield has a ramified effect on lactation performance of the animals. Animals selected for high 305-day milk yield (TMY) would also have increased peak milk yield (MYmax). This would be at reduced days in milk when peak milk yield is achieved (DIMP) and a relatively reduced persistency (S). From a physiological perspective, ascend in milk yield to peak after parturition is because of the increased secretory activity of the alveoli cells of the udder. After peak, the decline is because of loss of mammary cells owing to apoptosis (Dijkstra et al., 1997; Pollott, 2000; Capuco et al., 2003). Increased peak milk yield because of selection for high TMY at reduced DIMP, 
implies high alveoli activity in early lactation. This predisposes the animal to the disease risks associated with the peri-parturient period. Antagonistic genetic relationships between milk yield and udder health have been reported elsewhere in the literature (Negussie et al., 2008).

Increased milk yield in early stages of lactation (arising from high alveoli cell activity) because of selection for high TMY would lead to high-energy demand and consequently aggravate the condition of negative energy balance. At this time the animal undergoes hormonal involution, which depresses feed intake and energy metabolism. This may lead to reduced fertility in the form of high non-return rates (failure to return to oestrus), prolonged days open and silent heat. These conditions have been reported in high producing cows in some herds in Germany (El-Sysy, 2009). Milk letdown process is time bound and high milk yield is achieved when milking is done fast enough to empty the udder in less than 10 minutes from the onset of milking. In low-input production systems, where hand milking is common, cases of incomplete milking abound in high-yielding cows. This leads to early onset of apoptosis, high incidences of subclinical mastitis, and a decline in milk synthesis and secretion (Capuco et al., 2003). This may explain the rise in incidences of subclinical mastitis and reduction in productive herd life in high- producing dairy herds in Kenya.

Though a weak positive relationship existed between TMY and S (Table 3), targeting high TMY would result in a negative response in S owing to the high correlation between TMY and MYmax and the negative correlation between MYmax and DIMP, which in turn has a strong positive correlation with S. Similarly, selection for increased milk yield in Parity 1 would result in increased TMY and MYmax in subsequent parities and these are bound to have undesirable effects on S and DIMP. However, the magnitude of the changes in S and DIMP is dependent on the strength of the relationship between the traits.

In this study, the utility of milk yield records has been extended beyond selection for increased milk yield to explain lactation physiology using correlation estimates. However, owing to poor linkage of milk records between parities, the estimates have low reliability as depicted by relatively high standard errors and should be treated with caution. Therefore, the utility of milk yield records could be expanded, given good structural data characteristics.

\section{Conclusion}

Genetic and phenotypic correlations between traits in various parities show relationships of varied degrees. Selection of cows to increase total milk yield (TMY) would result in a positive correlated response of milk yield at peak lactation, but this would lead to positive or negative responses in persistency (S) and days in milk at peak lactation (DIMP), depending on the lactation. Selection for high TMY would influence the shape of the lactation curve, especially in early lactation, and hence could be the cause of the observed decline in fertility and increase in incidences of metabolic disorders. Consequently, a multi-trait, multiple lactation animal evaluation and selection should be considered. Selection decisions in lactation 1 may not have similar outcomes in lactations 2 and 3 . Selection at farm level should be optimized by using records from three parities, as is done in contract mating Test-day milk yield records submitted by producers should therefore be used in a variety of ways other than the traditional selection of animals based on total milk yield, thereby enhancing the utility of the records, which would augment the propensity of producers to participate in the national performance evaluation scheme.

\section{References}

Appuhamy, J.A.D.R.N., Cassell, B.G., Dechow, C.D. \& Cole, J.B., 2007. Phenotypic relationships of common health disorders in dairy cows to lactation persistency estimated from daily milk weights. J. Dairy Sci. 90, 4424-4434.

Bourdon, R.M., 2000. Understanding Animal Breeding. (2nd ed.). Prentice Hall, New Jersey, USA.

Capuco, A.V., Ellis, S.E., Hale, S.A., Long, E., Erdman, R.A., Zhao, X. \& Paape, M.J., 2003. Lactation persistency: Insights from mammary cell proliferation studies. J. Anim. Sci. 81, 18-31.

Cole, J.B. \& Null, D.J., 2009. Genetic evaluation of lactation persistency for five breeds of dairy cattle. J. Dairy Sci. 92, 2248-2258.

Dijkstra, J., France, J., Dhanoa, M.S., Maas, J.A., Hanigan, M.D., Rook, A.J. \& Beever, D.E., 1997. A model to describe growth patterns of the mammary gland during pregnancy and lactation. J. Dairy Sci. 80 , 2340-2354.

El-Sysy, M.A.I.M., 2009. Evaluation of reproductive performance of dairy cows. PhD thesis, HumboldtUniversitaet zu Berlin, Berlin, Germany.

Ilatsia, E.D., Muasya, T.K., Muhuyi, W.B. \& Kahi, A.K., 2007. Milk production and reproductive performance of Sahiwal cattle in semi arid Kenya. Trop. Sci. 47, 120-127. 
Jakobsen, H.J., Madsen, P., Jensen, J., Pedersen, J., Christensen, L.G. \& Sorensen, D.A., 2002. Genetic parameters for milk production and persistency for Danish Holsteins estimated in Random Regression models using REML. J. Dairy Sci. 85, 1607-1616.

Jamrozik, J., Bohmanova, J. \& Schaeffer, L.R., 2010. Relationships between milk yield and somatic cell score in Canadian Holsteins from simultaneous and recursive random regression models. J. Dairy Sci. 93, 1216-1233.

Meyer, K., 2006. WOMBAT - A program for mixed model analyses by restricted maximum likelihood. (User notes ed.). Animal Genetics and Breeding Unit, University of New England, Armidale.

Mrode, R.A., 2005. Linear Models for the Prediction of Animal Breeding Values. (2nd ed.). CABI Publishing, Wallingford, UK.

Muir, B.L., Fatehi, J. \& Schaeffer, L.R., 2004. Genetic relationships between persistency and reproductive performance in first-lactation Canadian Holsteins. J. Dairy Sci. 87, 3029-3037.

Muir, B.L., Kistemaker, G., Jamrozik, J. \& Canavesi, F., 2007. Genetic parameters for a multiple-trait multiple-lactation random regression test-day model in Italian Holsteins. J. Dairy Sci. 90, 1564-1574.

Negussie, E., Stranden, I. \& Mantysaari, E.A., 2008. Genetic association of clinical mastitis with test-day somatic cell score and milk yield during first lactation of Finnish Ayrshire cows. J. Dairy Sci. 91, 1189-1197.

Ojango, J.M.K. \& Pollott, G.E., 2001. Genetics of milk yield and fertility traits in Holstein-Friesian cattle on large scale Kenyan farms. J. Anim. Sci. 79, 1742-1750.

Pollott, G.E., 2000. A biological approach to lactation curve analysis for milk yield. J. Dairy Sci. 83, 2448-2458.

Rekaya, R., Carabano, M.J. \& Toro, M.A., 2000. Bayesian analysis of lactation curves of Holstein-Friesian cattle using a nonlinear model. J. Dairy Sci. 83, 2691-2701.

SAS, 2004. Base SAS 9.1 procedures guide. SAS Institute Inc., Cary, NC, USA.

Wood, P.D.P., 1967. Algebraic model of the lactation curve in cattle. Nature 216, 164-165. 